\title{
Article \\ The Influence of Liquid Medium Choice in Determination of Minimum Inhibitory Concentration of Essential Oils against Pathogenic Bacteria
}

\author{
Radka Hulankova (D)
}

Citation: Hulankova, R. The Influence of Liquid Medium Choice in Determination of Minimum Inhibitory Concentration of Essential Oils against Pathogenic Bacteria. Antibiotics 2022, 11, 150. https:// doi.org/10.3390/antibiotics11020150

Academic Editors: Carla Sabia and Ramona Iseppi

Received: 3 January 2022

Accepted: 22 January 2022

Published: 25 January 2022

Publisher's Note: MDPI stays neutral with regard to jurisdictional claims in published maps and institutional affiliations.

Copyright: (C) 2022 by the author. Licensee MDPI, Basel, Switzerland. This article is an open access article distributed under the terms and conditions of the Creative Commons Attribution (CC BY) license (https:// creativecommons.org/licenses/by/ $4.0 /)$
Department of Animal Origin Food and Gastronomic Sciences, Faculty of Veterinary Hygiene and Ecology, University of Veterinary Sciences Brno, 61242 Brno, Czech Republic; hulankovar@vfu.cz; Tel.: +420-541-562-750

\begin{abstract}
So far there is no internationally accepted, standardized method for MIC determination of natural substances such as essential oils (EOs). The aim of this study was to elucidate how much the MIC values obtained from various studies using different culture media are comparable. The median MICs for cinnamon essential oil (EO) obtained by broth dilution were 517, 465 and $517 \mu \mathrm{g} / \mathrm{mL}$ for Mueller-Hinton Broth (MHB), Tryptone Soya Broth (TSB) and Brain Heart Infusion (BHI), respectively. The MIC values for oregano EO were significantly $(p<0.001)$ lower in MHB than in highly nutritious media; the median MICs were $616 \mu \mathrm{g} / \mathrm{mL}$ for MHB and $474 \mu \mathrm{g} / \mathrm{mL}$ for TSB and BHI. This statistically significant difference was noted for all the pathogens studied (Salmonella Enteritidis, Escherichia coli O157, Listeria monocytogenes, Staphylococcus aureus). In the presence of oregano EO lag phase was also much less prolonged in MHB (by 6-17\%) than in the other media (by $92-189 \%$ ). Some components of EOs may bind to starch in MHB; since the phenomenon seems to be selective and EO dependent, the use of MHB for comparison of antimicrobial properties of various EOs thus cannot be recommended.
\end{abstract}

Keywords: minimum inhibitory concentration (MIC); broth microdilution method; essential oil; antimicrobial activity; growth kinetics

\section{Introduction}

The antimicrobial effect of essential oils (EOs) in vitro has been thoroughly studied in the past decades. The most common methods used for research of antimicrobial activity of EOs include diffusion methods (agar disk-diffusion method, antimicrobial gradient method (Etest), agar well diffusion method) and dilution techniques (agar dilution and broth macro and microdilution method). Whereas the diffusion methods are mostly based on measurement of an inhibition zone on agar plate, dilution methods are based on determination of MIC via growth/no growth end-point [1]. Agar and broth dilution are the most commonly used methods for determination of MIC of antimicrobial agents. Broth dilution uses liquid culture medium containing increasing concentrations (typically a twofold dilution series) of the antimicrobial substance and inoculation with a defined number of bacterial cells. The method is termed macrodilution when using a total volume in milliliters, or microdilution, if performed in microtiter plates using $\leq 500 \mu \mathrm{L}$ per well. The presence of turbidity or a sediment after incubation indicates growth of the microorganism. In both the agar and the broth dilution techniques, the MIC is defined as the lowest concentration of the antimicrobial substance that prevents visible growth of a microorganism under defined conditions [2].

The methods used for research of EOs are derived from the methods used for testing of antimicrobial susceptibility of microorganisms against antibiotics. These procedures have been honed for many years and standardized to allow for reproducibility. The Clinical and Laboratory Standards Institute's (CLSI's) protocols are accepted world-wide for testing of antibiotics. Both CLSI and EUCAST performance standards include cation-adjusted 
Mueller-Hinton broth and Mueller-Hinton agar as the appropriate growth medium for broth and agar dilution technique, respectively [3,4]. Although many studies on EOs uses these media, other broths and agars are commonly employed. Indeed, it is often very difficult to compare the results of antimicrobial effect in published articles due to the use of different non-standardized procedures [1]. Van de Vel et al. [5] created a review on methods for in vitro evaluating antimicrobial activity, based on analysis of data published between 1995-2016. The authors clearly identified the most important factors causing the variance in minimum inhibitory concentration (MIC) between studies, which included incubation conditions, culture media and the use of emulsifiers or solvents. Balouiri et al. [1] mention also other factors, e.g., inoculum size and end-points determination.

There have been numerous calls for an international standard method for evaluation of the antimicrobial activity of EOs and its compounds in order to achieve better comparability between studies [1,5]. One of the main parameters to establish would be the growth medium. Although Mueller-Hinton broth seems to be the logical choice for broth dilution, no evaluation was performed so far regarding the possible interactions between EOs components and the components in the culture medium, similar to interactions with food components (proteins, fat, starch) which have been previously reported [6].

The aim of this study was not a development of a new culture medium suitable for EOs evaluation, but a comparison of the most commonly used, clearly defined laboratory growth media including Mueller-Hinton broth in order to elucidate how much the MIC values obtained in different culture media are comparable.

\section{Results and Discussion}

This study focused on comparison of MHB, BHI and TSB as the most common media used for determination of MIC of EOs by broth dilution method. Generally, TSB showed significantly lower MIC values than MHB $(p<0.001)$ and $\mathrm{BHI}(p=0.006)$. However, further analysis revealed that $\mathrm{EO}$ also played a role. The most notable are the increased MIC values for oregano EO in MHB (median $616 \mu \mathrm{g} / \mathrm{mL}$ ) in comparison to other media with median $474 \mu \mathrm{g} / \mathrm{mL}$ (Table 1).

Table 1. Differences in MIC $(\mu \mathrm{g} / \mathrm{mL})$ between various essential oils and growth media $(n=24)$.

\begin{tabular}{ccccccc}
\hline \multirow{2}{*}{ Medium } & \multicolumn{2}{c}{ Oregano Essential Oil } & \multicolumn{3}{c}{ Cinnamon Essential Oil } \\
& Mean & Median & Min-Max & Mean & Median & Min-Max \\
\hline TSB & 466 & $474 \mathrm{Aa}$ & $379-569$ & 461 & $465^{\mathrm{Aa}}$ & $310-620$ \\
BHI & 482 & $474 \mathrm{Aa}$ & $379-664$ & 530 & $517^{\mathrm{Ba}}$ & $414-620$ \\
MHB & 604 & $616^{\mathrm{Ba}}$ & $474-758$ & 470 & $517^{\mathrm{Ab}}$ & $310-620$ \\
\hline
\end{tabular}

MIC, minimum inhibitory concentration; TSB, tryptone soya broth; BHI, brain heart infusion; MHB, MuellerHinton broth; min, minimal value; max, maximal value; ${ }^{a, b}$ mark statistically significant differences within a row; A,B mark statistically significant differences within a column.

The composition of BHI and TSB is similar, with BHI containing slightly more proteinous components $(28 \mathrm{~g} / \mathrm{L}$ ) than TSB with $20 \mathrm{~g} / \mathrm{L}$ (Table 2). MHB is on the other hand a far less complex medium containing a high amount of proteinous components $(317.5 \mathrm{~g} / \mathrm{L})$ and starch $(1.5 \mathrm{~g} / \mathrm{L})$. Proteins are known to interfere with the antimicrobial activity of EOs [6-10]. Increased MIC values of thymol and carvacrol in nutrient agar and TSB, respectively, were reported after addition of bovine serum albumin $[7,8]$. Oregano and thyme EOs were also less inhibitory against $L$. monocytogenes in TSB after addition of starch $(1 \%, 5 \%$ and $10 \%$ ), whereas the same oils did not bind to simple sugars represented mainly by glucose and fructose [6,9]. On the other hand, the increased MIC was not observed for cinnamon $\mathrm{EO}$, suggesting that the compounds of this oil do not bind to starch or proteins in the same manner as the oregano EO. Carvacrol, the main component of oregano EO, is a phenolic monoterpenoid, whereas cinnamaldehyde, the main component of cinnamon $\mathrm{EO}$, has an aldehyde group [5]. Furthermore, as there are differences between simple and complex saccharides, it should be further elucidated how the degree of hydrolyzation influences the binding of EO components to proteinous substances, as not only amount, but also the form 
could play a role in the interaction. While bovine serum albumin interfered negatively with EO compounds [7,8], addition of meat extract to TSB increased the efficacy of EOs [6] and of aqueous extract from rose fruits [10], although in the latter case the effect was clearly pronounced only for high concentration of the extract used. Although no deliberate comparison of the media in regard to EOs have been made so far, Serio et al. [11] reported growth of L. monocytogenes in both BHI and TSB after exposure to oregano EO. Lag phases in TSB were longer than in BHI, which corresponds with the results of our study (Table 3). The authors mention that BHI may favor the growth of cells stressed by EO due to the presence of osmoprotective carnitine, which can improve the cell resistance.

Table 2. Comparison of the liquid media composition $[\mathrm{g} / \mathrm{L}]$.

\begin{tabular}{|c|c|c|c|c|c|c|}
\hline \multirow[t]{2}{*}{ Broth } & \multicolumn{2}{|c|}{ Proteinous Components } & \multirow{2}{*}{$\begin{array}{c}\text { Glucose } \\
2.0\end{array}$} & \multirow{2}{*}{$\begin{array}{c}\text { Starch } \\
-\end{array}$} & \multirow{2}{*}{$\begin{array}{c}\text { Phosphate } \\
\text { Buffer }\end{array}$} & \multirow{2}{*}{$\begin{array}{c}\mathrm{NaCl} \\
5.0\end{array}$} \\
\hline & 12.5 & Brain infusion solids & & & & \\
\hline \multirow[t]{2}{*}{$\mathrm{BHI}$} & 5.0 & Beef heart infusion solids & & & & \\
\hline & 10.5 & Proteose peptone & & & & \\
\hline \multirow[t]{2}{*}{ TSB } & 17.0 & Pancreatic digest of casein & 2.5 & - & 2.5 & 5.0 \\
\hline & 3.0 & Enzymatic digest of soya & & & & \\
\hline \multirow[t]{2}{*}{ MHB } & 300.0 & Beef infusion & - & 1.5 & - & - \\
\hline & 17.5 & Casein hydrolysate & & & & \\
\hline
\end{tabular}

Table 3. Comparison of growth model parameters for various media (mean \pm SEM of three measurements).

\begin{tabular}{|c|c|c|c|c|c|c|c|}
\hline Strain & Medium & $\begin{array}{c}\text { OEO } \\
{[\mu \mathrm{g} / \mathrm{mL}]}\end{array}$ & $\begin{array}{c}\lambda \\
{[\mathbf{h}]}\end{array}$ & $\begin{array}{c}\mu_{\max } \\
{[\text { OD units } / h]}\end{array}$ & RMSE & $\begin{array}{l}\Delta \lambda \\
{[\%]}\end{array}$ & $\begin{array}{c}\Delta \mu_{\max } \\
{[\%]}\end{array}$ \\
\hline \multirow{6}{*}{$\begin{array}{l}\text { L. monocytogenes } \\
\text { ATCC } 13932\end{array}$} & $\mathrm{TSB}$ & 0 & $3.47 \pm 0.34$ & $0.37 \pm 0.03$ & $0.04 \pm 0.00$ & $+189 \%$ & $-70 \%$ \\
\hline & & 284 & $10.04 \pm 0.56$ & $0.11 \pm 0.02$ & $0.04 \pm 0.01$ & & \\
\hline & $\mathrm{BHI}$ & 0 & $4.59 \pm 0.31$ & $0.30 \pm 0.01$ & $0.03 \pm 0.00$ & $+92 \%$ & $-60 \%$ \\
\hline & & 284 & $8.81 \pm 0.50$ & $0.12 \pm 0.01$ & $0.05 \pm 0.01$ & & \\
\hline & MHB & 0 & $5.15 \pm 0.37$ & $0.10 \pm 0.01$ & $0.02 \pm 0.00$ & $+17 \%$ & $-30 \%$ \\
\hline & & 284 & $6.01 \pm 0.41$ & $0.07 \pm 0.01$ & $0.03 \pm 0.00$ & & \\
\hline \multirow{6}{*}{$\begin{array}{c}\text { E. coli O157 } \\
\text { ATCC } 700728\end{array}$} & TSB & 0 & $3.43 \pm 0.36$ & $0.27 \pm 0.03$ & $0.02 \pm 0.01$ & $+172 \%$ & $-59 \%$ \\
\hline & & 284 & $9.35 \pm 0.49$ & $0.11 \pm 0.01$ & $0.04 \pm 0.01$ & & \\
\hline & $\mathrm{BHI}$ & 0 & $3.88 \pm 0.35$ & $0.27 \pm 0.04$ & $0.02 \pm 0.00$ & $+113 \%$ & $-41 \%$ \\
\hline & & 284 & $8.72 \pm 0.58$ & $0.16 \pm 0.02$ & $0.05 \pm 0.01$ & & \\
\hline & MHB & 0 & $4.29 \pm 0.41$ & $0.19 \pm 0.02$ & $0.03 \pm 0.01$ & $+6 \%$ & $-26 \%$ \\
\hline & & 284 & $4.54 \pm 0.53$ & $0.14 \pm 0.04$ & $0.01 \pm 0.01$ & & \\
\hline
\end{tabular}

SEM standard error of the mean; OEO, oregano essential oil; $\lambda$, lag phase duration estimation; $\mu_{\max }, \operatorname{maximum}$ specific growth rate estimation; RMSE, root-mean-square error (OD units); $\Delta$ increase/decrease of the parameter in OEO in comparison to control.

In a study by Granata et al. [12], encapsulated oregano (thymol chemotype) and thyme (carvacrol chemotype) EOs were tested on various pathogens. The MIC of L. monocytogenes determined in BHI was significantly lower $(0.03 \mathrm{mg} / \mathrm{mL})$ than the MICs of S. aureus and E. coli grown in $\mathrm{MHB}(0.06$ and $0.12 \mathrm{mg} / \mathrm{mL}$, respectively). On the other hand, in a study of Simionato et al. [13], encapsulated cinnamon EO exhibited the same MIC for L. monocytogenes in BHI as for E. coli O157 and Y. enterocolitica in MHB. Although the encapsulation, strain specificity and other factors could play a role in the differences (or the lack of them), these data could also corroborate the specific binding of EO compounds to MHB compounds. Our results from the MIC assay were supported by the values of growth kinetic parameters. While the lag phase duration doubled in BHI and almost tripled in TSB in the presence of oregano EO in comparison to control (Table 3), it was prolonged only by $6-17 \%$ in MHB. The maximum growth rate also decreased the less in MHB in the presence of oregano $\mathrm{EO}$ in comparison to control. 
The differences between the reference strain and the mixture of food isolates (Figure 1) were statistically significant for all the species except Salmonella Enteritidis. The most pronounced difference was found for $S$. aureus $(p<0.001)$ with median $414 \mu \mathrm{g} / \mathrm{mL}$ for reference strain and $569 \mu \mathrm{g} / \mathrm{mL}$ for mixture of food isolates. These differences were not affected by the type of growth medium or essential oil. The use of mixture of contemporary food isolates represents a worst-case-scenario, where the most resistant strain will prevail. Since testing of numerous isolates individually is laborious, this approach may bring more precise results than the use of a single reference strain, although well defined.

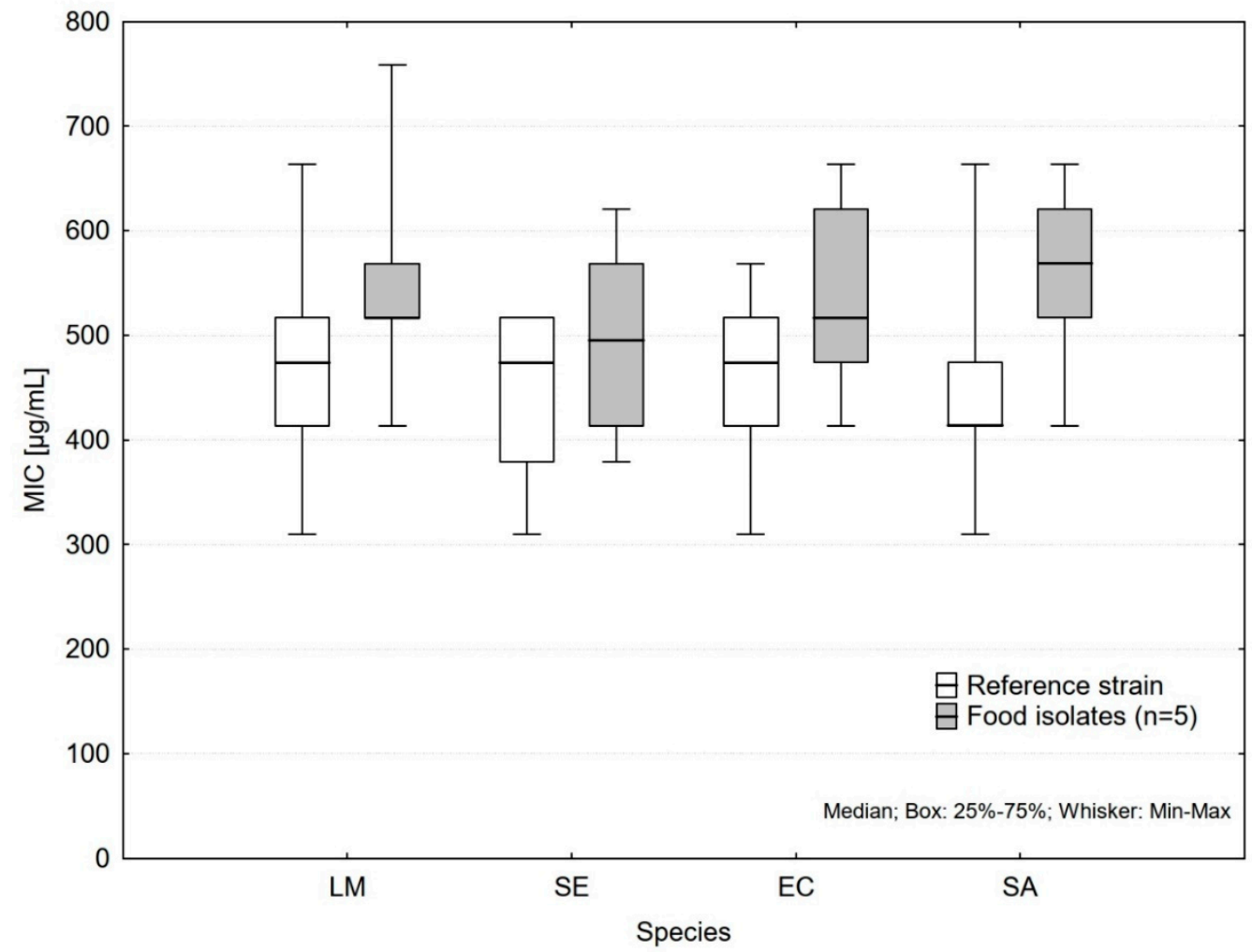

Figure 1. Differences in MIC between reference strains and mixtures of food isolates (LM, Listeria monocytogenes; SE, Salmonella Enteritidis; EC, Escherichia coli O157; SA, Staphylococcus aureus).

During evaluation of the interaction of medium type with other factors, statistically significant interaction was found between species and EO (Table 4), but not between species, EO and medium (Figure 2), meaning that the differences between species were approx. the same in all the media. It should be mentioned that L. monocytogenes is usually cultivated in TSB with yeast extract; however, the growth in TSB in our study was luxuriant enough to enable the species comparison using the same medium. On the other hand, no strains were able to grow in MHB without lysed blood supplementation. Although the supplementation is in CLSI standards for antimicrobial susceptibility testing [14], many studies testing EOs against L. monocytogenes in MHB do not mention this M45 standard or any supplementation [15-20] and in another study only MHB for Streptococcus spp. was supplemented, although L. monocytogenes was included in the study [21]. This ambiguity in medium specification or supplementation decreases between-studies comparability of results obtained in $\mathrm{MHB}$. 
Table 4. Differences in MIC ( $\mu \mathrm{g} / \mathrm{mL})$ between various essential oils and pathogens $(n=18)$.

\begin{tabular}{ccccccc}
\hline \multirow{2}{*}{ Medium } & \multicolumn{3}{c}{ Oregano Essential Oil } & \multicolumn{3}{c}{ Cinnamon Essential Oil } \\
& Mean & Median & Min-Max & Mean & Median & Min-Max \\
\hline Salmonella Enteritidis & 442 & $474 \mathrm{Aa}$ & $379-569$ & 506 & $517 \mathrm{Aa}$ & $310-620$ \\
Escherichia coli O157 & 500 & $474 \mathrm{ABa}$ & $379-664$ & 494 & $517 \mathrm{Aa}$ & $310-620$ \\
Listeria monocytogenes & 569 & $569 \mathrm{Ba}$ & $474-758$ & 483 & $517 \mathrm{Ab}$ & $310-620$ \\
Staphylococcus aureus & 558 & $569 \mathrm{Ba}$ & $379-664$ & 465 & $414 \mathrm{Ab}$ & $310-620$ \\
\hline
\end{tabular}

MIC, minimum inhibitory concentration; min, minimal value; max, maximal value; ${ }^{\mathrm{a}, \mathrm{b}}$ mark statistically significant differences within a row; ${ }^{\mathrm{A}, \mathrm{B}}$ mark statistically significant differences within a column.
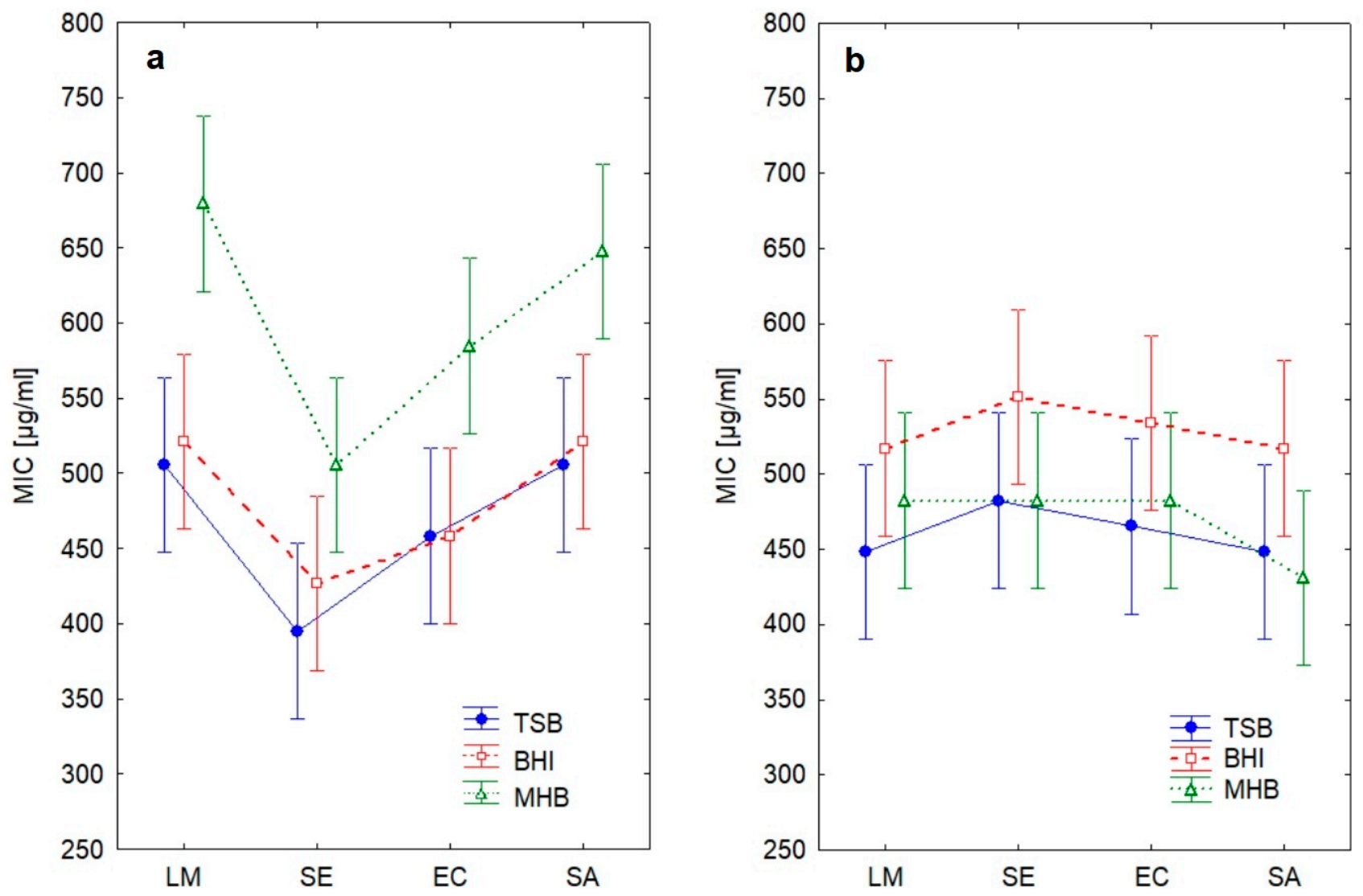

Figure 2. Differences in MIC between essential oils, growth media and pathogens (LM, Listeria monocytogenes; SE, Salmonella Enteritidis; EC, Escherichia coli O157; SA, Staphylococcus aureus). (a) Oregano essential oil; (b) cinnamon essential oil.

Statistically significant interaction was found between species and EO (Table 4); whereas the differences between species were not significant when cinnamon EO was used, for oregano EO the MIC of Salmonella Enteritidis was significantly lower than the MICs of L. monocytogenes and S. aureus ( $p=0.009$ and 0.015 , respectively). For the Gram positive bacteria, the MIC values were higher for oregano EO than for cinnamon EO ( $p=0.002$ and 0.003 for L. monocytogenes and S. aureus, respectively). On the other hand, the Gram negative bacteria showed opposite results (although the difference was not statistically significant). This is in accordance with the reported correlation of EOs' composition with their antimicrobial properties published by Bagheri et al. [22], where phenols were the most inhibitory against Salmonella enterica and E. coli, whereas aldehydes were the most inhibitory against $S$. aureus. 


\section{Materials and Methods}

\subsection{Bacterial Strains}

Reference strains of four major food pathogens were used for the media testing: Escherichia coli O157 (ATCC 700728), Salmonella Enteritidis (ATCC 13076), Listeria monocytogenes (ATCC 13932) and Staphylococcus aureus (ATCC 25923). Simultaneously, for each species a mixture of five wild strains isolated from meat and meat products and preparations was used in order to count for strain variability. Specification of the bacterial isolates is available in Appendix A, Table A1. The bacterial cultures were kept frozen at $-70{ }^{\circ} \mathrm{C}$.

\subsection{Essential Oils}

Commercial essential oils (EOs) from oregano (Origanum vulgare, Spain) and cinnamon (Cinnamomum zeylanicum, Sri Lanka) obtained by steam distillation were purchased from Nobilis Tilia, Krásná Lípa, Czech Republic. Complete chemical composition of each oil (determined by GC-MS in an accredited laboratory in Germany, where the oils were manufactured by Joh. Vögele KG) is available in Appendix A, Figure A1. In short, the main components of oregano EO (density $0.948 \mathrm{~g} / \mathrm{mL}$ ) were carvacrol $(73.6 \%)$, p-cymene $(7.0 \%)$ and $\gamma$-terpinene $(6.0 \%)$. The main components of cinnamon EO (density $1.034 \mathrm{~g} / \mathrm{mL}$ ) were trans-cinnamaldehyde (65\%), eugenol (18.0\%) and $\beta$-caryophyllene (4.9\%).

\subsection{Determination of Minimum Inhibitory Concentration}

Minimum inhibitory concentration (MIC) was determined by broth microdilution method. All the culture media used in this study were purchased from Oxoid, UK. The strains were plated on Tryptone Soya Agar (TSA, CM0131), Mueller-Hinton Agar (MHA, CM0337) and Brain Heart Infusion Agar (BHIA, CM1136) and once more subcultivated at $37^{\circ} \mathrm{C} / 24 \mathrm{~h}$. Bacterial suspension was prepared in saline using the McFarland turbidity scale and further diluted to approximately $1 \times 10^{6}$ cells $/ \mathrm{mL}$. According to the agar used for subcultivation, Tryptone Soya Broth (TSB, CM0129), Mueller-Hinton Broth (MHB, CM0405) or Brain Heart Infusion broth (BHI, CM1135) were used as the diluent. Since L. monocytogenes didn't grow in pure MHB, Laked Horse Blood (SR0048) was added into $\mathrm{MHB}$ to make for final concentration $5 \%$ according to the international standards $[4,14]$.

Essential oils were individually diluted in TSB, MHB and BHI (1:1) and vortexed vigorously. The emulsions were further diluted to a working concentration of $1 \%$, from which a concentration row from $0.02-0.2 \%(v / v)$ was prepared. The dilutions of EOs were mixed $1: 1$ with the inoculum in a 96 -well microplate. Both positive $(0 \% \mathrm{EO})$ and negative (uninoculated solutions of EO) controls were included. The plates were incubated at $37^{\circ} \mathrm{C}$ for $24 \mathrm{~h}$. MIC was determined as the lowest concentration required to prevent visible growth. The whole experiment was twice replicated $(n=3)$. The media composition is showed in Table 2.

\subsection{Growth Kinetics Measurements}

The growth curves were constructed based on optical density (OD) measurement at $850 \mathrm{~nm}$ in Personal Bioreactor RTS-1 (Biosan, Riga, Latvia). Both control measures and measures in media with $0.03 \%(284 \mu \mathrm{g} / \mathrm{mL})$ of oregano essential oil (approx. $50 \%$ of MIC) were performed. Since EOs are highly volatile substances, maximum volume (30 $\mathrm{mL})$, sealed tubes and no tube rotation were used in order to prevent increased evaporation. The media were spiked with inoculum prepared as described above (with the same final concentration of approximately $5 \times 10^{5}$ cells $/ \mathrm{mL}$ ) and incubated at $37^{\circ} \mathrm{C}$ in the machine until the stationary phase was achieved. The OD was measured at 10 min intervals. For growth kinetics only reference strains of E. coli $\mathrm{O} 157$ and L. monocytogenes were used, since the factory calibration of the instrument is designed for specific microorganism size of $0.4-0.8 \times 1-3 \mu \mathrm{m}$. Each measurement was performed three times. 


\subsection{Statistical Analysis}

Since the dependent variable (MIC) was represented by interval, censored and nonnormally distributed data, non-parametric statistical methods were used. Multiple comparisons were done by Wilcoxon (paired) test and the $p$-values were adjusted using Holm correction [23] with the $p$ level of 0.05 set as statistically significant. Since there are no well-recognized non-parametric tests for multiple factors/mixed design, the interaction of media type with other factors (EO, Species, Origin) was assessed from the pairwise plots and verified by multiple comparisons. The species were compared using Kruskal-Wallis ANOVA and multiple comparisons of mean ranks. The computations were done in Statistica, v. 7.1 (StatSoft, Tulsa, OK, USA) and in Microsoft Excel 2016 (Microsoft, Redmond, WA, USA).

Growth curves (OD values) were fitted in Microrisk Lab online predictor v1.2 [24] using primary growth model of Baranyi as the best fit [25] in order to compute maximum specific growth rate $\left(\mu_{\max }\right)$ and lag phase duration $(\lambda)$.

\section{Conclusions}

The results show that the MIC values obtained by broth dilution using highly nutritious media such as TSB and BHI are fully comparable. On the other hand, the MIC values for oregano EO were significantly lower in MHB for all the pathogens, probably due to an interaction of its components with starch and reduced ability of the bacteria to repair the cell damage in a nutrient-deficient medium. Although there is still no internationally accepted, standardized method for MIC determination of natural substances such as EOs, MHB and MHA are the most commonly used media for broth and agar dilution, respectively. Admittedly, the MIC values for oregano EO in MHB were lower by $122-138 \mu \mathrm{g} / \mathrm{mL}$ than in TSB and BHI, which is not an enormous difference. However, the difference may not only hamper comparison of results from different studies using different media, but also the comparison of EOs conducted within a study, as not all the EOs are affected by starch in the same manner. Thus, the use of MHB for determination of antimicrobial properties of EOs is not ideal. The lowest MIC values were obtained in TSB which seems the most suitable candidate for reference medium in any future standard method for antimicrobial testing of EOs by broth dilution method. The medium in its basic composition better supports the growth of fastidious bacteria such as Listeria monocytogenes, without the need to specify whether cation adjustment/blood supplementation was used or not.

Funding: This research was funded by the Institutional Research Support for University of Veterinary Sciences Brno.

Institutional Review Board Statement: Not applicable.

Informed Consent Statement: Not applicable.

Data Availability Statement: All the data are available from the corresponding author upon reasonable request.

Acknowledgments: The author is grateful to the company Nobilis Tilia for providing chemical composition of the EOs batches including the chromatograms.

Conflicts of Interest: The author declares no conflict of interest. 


\section{Appendix A}

Table A1. Bacterial isolates used in the study.

\begin{tabular}{cccc}
\hline Species & Specification & Isolated & Source \\
\hline Escherichia coli & serotype O157 & 2015 & pork meat preparation \\
Escherichia coli & serotype O157 & 2017 & wild boar carcass \\
Escherichia coli & serotype O157 & 2017 & wild boar carcass \\
Escherichia coli & serotype O157 & 2018 & sushi \\
Escherichia coli & serotype O157 & 2019 & duck carcass \\
\hline Listeria monocytogenes & serotype 1/2a & 2014 & chicken carcass \\
Listeria monocytogenes & serotype 1/2a & 2014 & chicken carcass \\
Listeria monocytogenes & serotype 1/2b & 2018 & cooked meat product \\
Listeria monocytogenes & serotype 1/2b & 2018 & cooked meat product \\
Listeria monocytogenes & serotype 1/2c & 2015 & pork meat preparation \\
\hline Salmonella Enteritidis & phage type $1 \mathrm{~b}$ & 2015 & poultry meat preparation \\
Salmonella Enteritidis & phage type 4 & 2015 & poultry meat preparation \\
Salmonella Enteritidis & phage type $4 \mathrm{~b}$ & 2016 & minced turkey meat \\
Salmonella Enteritidis & phage type 8 & 2014 & chicken carcass \\
Salmonella Enteritidis & phage type 13 & 2014 & chicken carcass \\
\hline Staphylococcus aureus & - & 2015 & pork meat preparation \\
Staphylococcus aureus & - & 2015 & cooked meat product \\
Staphylococcus aureus & - & 2019 & duck carcass \\
Staphylococcus aureus & - & duck carcass \\
Staphylococcus aureus & - & cooked meat product
\end{tabular}
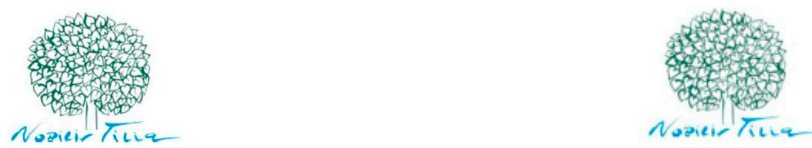

\section{ANALYTICAL CERTIFICATE}

$\begin{array}{ll}\text { NAME: } & \text { ESSENTIAL OIL CINNAMON } \\ \text { CODE: } & \text { E0074 } \\ \text { INCI: } & \text { Cinnamomum Zeylanicum Bark Oil } \\ \text { BATCH NO. } & 12.3 .2018 \\ \text { EXP. } & 12.3 .2020\end{array}$

$\begin{array}{ll}\text { ANALYTICAL CERTIFICATE } \\ \text { NAME: } & \text { ESSENTIAL OIL OREGANO } \\ \text { CODE: } & \text { EO110 } \\ \text { INCI: } & \text { Origanum Vulgaris Oil } \\ \text { BATCH NO. } & 2.11 .2017 \\ \text { EXP. } & 2.11 .2019\end{array}$

DENSITY $\left(20^{\circ} \mathrm{C}\right) \quad 0.948 \mathrm{~g} / \mathrm{cm}^{3}$

REFRACTIVE INDEX $\left(20^{\circ} \mathrm{C}\right) \quad 1.508$

OPTICAL ROTATION $\left(20^{\circ} \mathrm{C}\right) \quad 0^{\circ}$

\begin{tabular}{lc} 
COMPONENT & $\%$ \\
\hline Alpha-Pinene & 0.776 \\
Alpha-Terpinene & 1.186 \\
Alpha-Thujene & 1.516 \\
Beta-caryophyllene & 2.141 \\
Beta-Pinene & 0.200 \\
Borneol & 0.217 \\
Gamma-Terpinene & 6.026 \\
Camphen & 0.237 \\
Carvacrol & 73.561 \\
Limonene & 0.331 \\
Linalool & 0.100 \\
Myrcen & 2.161 \\
Para-Cymen & 6.972 \\
Terpin-1-en-4-ol & 0.788
\end{tabular}

(b)

Figure A1. Analytical certificates. (a) chemical composition of cinnamon essential oil; (b) chemical composition of oregano essential oil. 


\section{References}

1. Balouiri, M.; Sadiki, M.; Ibnsouda, S.K. Methods for in vitro evaluating antimicrobial activity: A review. J. Pharm. Anal. 2016, 6, 71-79. [CrossRef] [PubMed]

2. Wiegand, I.; Hilpert, K.; Hancock, R.E.W. Agar and broth dilution methods to determine the minimal inhibitory concentration (MIC) of antimicrobial substances. Nat. Protoc. 2008, 3, 163-175. [CrossRef] [PubMed]

3. CLSI. M07: Methods for Dilution Antimicrobial Susceptibility Tests for Bacteria That Grow Aerobically, 11th ed.; CLSI: Wayne, PA, USA, 2018; pp. 1-112.

4. EUCAST. Media Preparation for EUCAST Disk Diffusion Testing and for Determination of MIC Values by the Broth Microdilution Method, Version 6.0; EUCAST: Växjö, Sweden, 2020; pp. 4-5. Available online: https://www.eucast.org/fileadmin/src/ media/PDFs/EUCAST_files/Disk_test_documents/2020_manuals/Media_preparation_v_6.0_EUCAST_AST.pdf (accessed on 21 October 2021).

5. Van de Vel, E.; Sampers, I.; Raes, K. A Review on influencing factors on the minimum inhibitory concentration of essential oils. Crit. Rev. Food Sci. Nutr. 2019, 59, 357-378. [CrossRef]

6. Gutierrez, J.; Barry-Ryan, C.; Bourke, P. The antimicrobial efficacy of plant essential oil combinations and interactions with food ingredients. Int. J. Food Microbiol. 2008, 124, 91-97. [CrossRef] [PubMed]

7. Juven, B.J.; Kanner, J.; Schved, F.; Weisslowicz, H. Factors that interact with the antibacterial action of thyme essential oil and its active constituents. J. Appl. Bacteriol. 1994, 76, 626-631. [CrossRef]

8. Veldhuizen, E.J.; Creutzberg, T.O.; Burt, S.A.; Haagsman, H.P. Low temperature and binding to food components inhibit the antibacterial activity of carvacrol against Listeria monocytogenes in steak tartare. J. Food Prot. 2007, 70, 2127-2132. [CrossRef]

9. Gutierrez, J.; Barry-Ryan, C.; Bourke, P. Antimicrobial activity of plant essential oils using food model media: Efficacy, synergistic potential and interactions with food components. Food Microbiol. 2009, 26, 142-150. [CrossRef] [PubMed]

10. Cendrowski, A.; Kraśniewska, K.; Przybył, J.L.; Zielińska, A.; Kalisz, S. Antibacterial and antioxidant activity of extracts from rose fruits (Rosa rugosa). Molecules 2020, 25, 1365. [CrossRef]

11. Serio, A.; Chiarini, M.; Tettamanti, E.; Paparella, A. Electronic paramagnetic resonance investigation of the activity of Origanum vulgare L. essential oil on the Listeria monocytogenes membrane. Lett. Appl. Microbiol. 2010, 51, 149-157. [CrossRef]

12. Granata, G.; Stracquadanio, S.; Leonardi, M.; Napoli, E.; Malandrino, G.; Cafiso, V.; Stefani, S.; Geraci, C. Oregano and thyme essential oils encapsulated in chitosan nanoparticles as effective antimicrobial agents against foodborne pathogens. Molecules 2021, 26, 4055. [CrossRef] [PubMed]

13. Simionato, I.; Domingues, F.C.; Nerín, N.; Silva, F. Encapsulation of cinnamon oil in cyclodextrin nanosponges and their potential use for antimicrobial food packaging. Food Chem. Toxicol. 2019, 132, 110647. [CrossRef] [PubMed]

14. CLSI. M45: Methods for Antimicrobial Dilution and Disk Susceptibility Testing of Infrequently Isolated or Fastidious Bacteria, 3rd ed.; CLSI: Wayne, PA, USA, 2016; p. 44.

15. Bouarab-Chibane, L.; Forquet, V.; Lanteri, P.; Clement, Y.; Leonard-Akkari, L.; Oulahal, N.; Degraeve, P.; Bordes, C. Antibacterial properties of polyphenols: Characterization and QSAR (Quantitative Structure-Activity Relationship) models. Front. Microbiol. 2019, 10, 829. [CrossRef] [PubMed]

16. Chaleshtori, F.D.; Saholi, M.; Chaleshtori, R.S. Chemical composition, antioxidant and antibacterial activity of Bunium persicum, Eucalyptus globulus, and rose water on multidrug-resistant Listeria species. J. Evid.-Based Integr. Med. 2018, 23, 2515690X17751314. [CrossRef] [PubMed]

17. Kang, J.H.; Song, K.B. Combined washing effect of noni extract and oregano essential oil on the decontamination of Listeria monocytogenes on romaine lettuce. Int. J. Food Sci. 2020, 55, 3515-3523. [CrossRef]

18. Puškárová, A.; Bučková, M.; Kraková, L.; Pangallo, D.; Kozics, K. The antibacterial and antifungal activity of six essential oils and their cyto/genotoxicity to human HEL 12469 cells. Sci. Rep. 2017, 7, 8211. [CrossRef]

19. Saraiva, C.; Silva, A.C.; Garcia-Diez, J.; Cenci-Goga, B.; Grispoldi, L.; Silva, A.F.; Almeida, J.M. Antimicrobial activity of Myrtus communis L. and Rosmarinus officinalis L. essential oils against Listeria monocytogenes in cheese. Foods 2021, 10, 1106. [CrossRef]

20. Shahbazi, Y. Chemical composition and in vitro antibacterial activity of Mentha spicata essential oil against common food-borne pathogenic bacteria. J. Pathog. 2015, 916305. [CrossRef]

21. Limsuwan, C.; Subhadhirasakul, S.; Voravuthikunchai, S.P. Medicinal plants with significant activity against important pathogenic bacteria. Pharm. Biol. 2009, 47, 683-689. [CrossRef]

22. Bagheri, L.; Khodaei, N.; Salmeri, S.; Karboune, S.; Lacroix, M. Correlation between chemical composition and antimicrobial properties of essential oils against most common food pathogens and spoilers: In-vitro efficacy and predictive modelling. Microb. Pathog. 2020, 147, e104212. [CrossRef]

23. Holm, S. A simple sequentially rejective multiple test procedure. Scand. J. Stat. 1979, 6, 65-70.

24. Liu, Y.; Wang, X.; Liu, B.; Dong, Q. Microrisk Lab: An online freeware for predictive microbiology. Foodborne Pathog. Dis. 2021, 18, 607-615. [CrossRef] [PubMed]

25. Baranyi, J.; Roberts, T.A. Mathematics of predictive food microbiology. Int. J. Food Microbiol. 1995, 26, 199-218. [CrossRef] 